\title{
Stress analysis of biomass fuel molding machine piston type stamping forming cone
}

\author{
Gaofeng $\mathrm{WU}^{1}$ a , Guanghui $\mathrm{Xu}^{1}$, Baoqian $\mathrm{Li}^{1 \mathrm{~b}}$ \\ ${ }^{1}$ Henan Agricultural University, China
}

\begin{abstract}
It is established the ram biomass straw machine as the analysis object in this paper,the molding machine cones of stress in the forming process of the analysis of the system. We used pottery instead of Wear-resistant cast iron for improving the performance of forming sleeve. The structure of the forming sleeve was analyzed with the mechanical module of a soft named Pro/engineer in this paper. The result indicated that the program was feasible. With the sensitivity analysis we identified the suitable angle for the sleeve.
\end{abstract}

\section{Introduction}

To enter in twenty-first Century, especially since 2005, energy environmental issues have become increasingly prominent, the prices of energy continue rising ${ }^{[1]}$. Governments have made great efforts to solve the energy shortage and environmental degradation problems. China is an agricultural county, with abundant biomass resources ${ }^{[2]}$. Statistically, biomass resource that only crop straws and firewood can be developed is up to 8 hundred million tons annually in China ${ }^{[3-4]}$. Deduction of industry, straws, feed and peasants living scattered burning consumed part, there are about 4.5 hundred million tons straws can be used for the production of $\mathrm{SDBF}^{[5]}$. Furthermore with the continuous improvement of comprehensive agricultural production level Chinese, China straws yield overall showed a rising trend ${ }^{[6]}$. The biomass solid forming fuel technology is one of the main direction development which is the development and utilization of biomass energy technology, not only can provide domestic energy but also can be used as industrial boiler and power plant fuel instead of coal, natural gas, fuel oil and other fossil energy ${ }^{[7]}$, also provide a good way for efficient reuse of agricultural and forestry wastes,including crop straws. To effectively solve the problem that the waste biomass is the occupation of cultivated land, wast of resources and destruction of the ecological environment ${ }^{[8]}$. A powerful impetus to the Chinese government in 2003 proposed fully completed in 2020 the overall objective of building a well-off society in an early realization ${ }^{[9]}$.

Although many kinds of biomass briquetting machine, forming technology is also mature, the widespread use of molding parts is easy to wear, the weakness of short life. In order to solve this problem, Henan Agricultural University was the first to put forward to using wear resistant ceramic material for forming easy wear parts.
Experimental results show that wear resistant ceramic material over ordinary metal wear stronger resistant material with abrasion resistance[3]. The designs of forming cone forming cone angle and shape retention period length are the main factors of affecting the friction force and the molding pressure, also the main factors which effects on forming cone tube wear rate[10]. This study based on finite element analysis of non metal ceramic cone, diagram a cone on stress distribution, the solution of a reasonable range of forming cone angle, to provide the basis for further improving the forming cone cylinder design.

\section{The forming theory of piston stamping straw forming machine}

The most applications of piston stamping straw forming equipment were mechanical drive type and hydraulic driven type. Hydraulic driving type was characterized by the use of pre-compaction of extrusion material. At work, oil pump driven by the motor, the hydraulic oil is fed into the cylinder cavity, convert electric energy into fluid pressure energy. The drive piston, piston rod, punch to end movement. As the piston rod forward thrust, the material entered the stable forming zone. Punch pressure in this area piston increased rapidly. Further eliminate gas existed in the biomass materials, stuck together, pile up and inlay, the volume was greatly reduced, density increase obviously ${ }^{[11-12]}$. The volume was greatly reduced, density increasing obviously. Gradually reduced along with the shaping cone aperture, the extrusion effect was getting stronger. In forming cone cylinder, biomass fuel internal bonded together, external carbonization and with a certain shape and strength.

As the piston punch reciprocating motion, the molding rod setting district, constantly being pushed new

\footnotetext{
a Author: Gaofeng Wu, wugaofeng5@126.com. ${ }^{\mathrm{b}}$ Corresponding author: Baoqian Li, nj280@163.com.
} 
molding materials. Under the action of the security type tube radial force, the cylinder wall and forming cone friction and adjacent forming block axial force keep it in shape. Finally, it was extruded from the conservation type tube into fuel products. Then the process was completed $^{[3]}$.
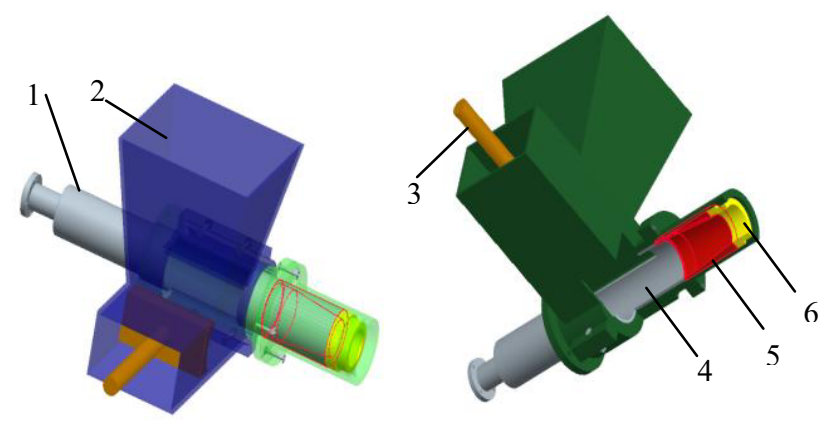

1. Piston punch 2. The feeding hopper 3. Preloading push rod 4. Punch set 5 . Forming cone 6 . Security type tube

Figure 1. The structure of molding position in the briquette equipment.

The forming part of the structure of hydraulic piston stamping straw forming machine is showed in Figure 1. The molding temperature is $160 \sim 200{ }^{\circ} \mathrm{C}$ while it is working. The pressure of forming is $4 \sim 8 \mathrm{MPa}^{[12]}$. The working conditions are extremely poor. After them from the feeding hopper into the molding machine the biomass material by preloading device for preloaded materials and then made them into a punch set. As the piston punch moves to the right, the materials are moving from punch set to the forming cone direction. Due to the hindrance formed cone cylinder on the material forward, the material density increases as the piston punch moves to the right in the punch set. The material has a great force of forming cone.

\section{Finite element analysis of ceramic forming cone ${ }^{[13][14]}$}

\subsection{The static analysis of the ceramic forming cone}

\subsubsection{The establishment of 3D model of the ceramic forming cone}

Use pro/engineer standard procedure draw a length of about $260 \mathrm{~mm}$ shape is a cylinder, the internal sleeve of a taper hole three dimensional physical model[13][14]. In case mutations produce and the accuracy affected, the model of the inverted and rounded is ignore while the finite element meshing. When normal working,the molding machine made the materials that came from the big hole forming cone is extruded from the small hole sleeve into the other end, completing the material molding. The sleeve big hole end has a section is a cylindrical hole which is taking into account the effect of taper on forming cone. So the length of the design is constant, small hole end aperture invariant and which is convenient to change sleeve taper and analyze by finite element analysis. Forming cone cylinder shape is shown as the number 5 in Fig. 1.

\subsubsection{The definition of load and constraint conditions}

The sleeve is arranged and fixed on the internal molding machine. While working the sleeve relative molding machine without displacement. The pressure of the material acted on the inside cone's conical surface. Based on the main design parameters of HPB-type IV biomass molding machine, the working pressure of molding machine main hydraulic cylinder is $10 \mathrm{MPa}$. The main hydraulic cylinder diameter is $200 \mathrm{~mm}$. Master cylinder punch on the material can produce a pressure of $314.2 \mathrm{KN}$. The final forming cone materials to withstand the pressure of $314.2 \mathrm{KN}$. End of cone and shape retention sleeve is fixed together. So add 6 degree of freedom displacement constraint in this end. Cone material existing molding machine using MT-4 wear resistant cast iron. Machinability of cast iron material is not good. Therefore the conical surface roughness is often poor. While the poor roughness sleeve is very easy to cause the biomass in the taper hole at the closed. So the preliminary ideas for alumina ceramics as the cone material, in order to overcome the shortcomings of cast iron.Alumina ceramics with high mechanical strength,corrosion resistance, high temperature resistance etc ${ }^{[15]}$. Consistent with the molding machine working conditions for forming cone material requirements. Here the alumina ceramic was chosen for the porcelain, the modulus of elasticity is $340 \mathrm{GPa}$, the Poisson's ratio of 0.22 , the density of $3.92 \mathrm{~g} / \mathrm{cm} 3$, the tensile strength of $160 \mathrm{MPa}$, the thermal expansion coefficient of $8.5 \times 10-6 / \mathrm{k}^{[3]}$. According to this as the entity model of cone added load, constraint and the definition of model material.

\subsubsection{The grid division}

Carries on the grid division of the 3D geometric model. Because the sleeve model for the rules of geometry, so the tetrahedral element, shape of triangle and quadrilateral mixed. Finite element analysis of precision and efficiency and cell density and geometry are closely related. Control factor on the division made some adjustments, the grid finer, to improve the accuracy of calculation, avoid grid deformity. And the calculation and analysis of complete. Is divided into 240 units, 442 nodes. The three-dimensional model of the mesh as shown in Figure 2.

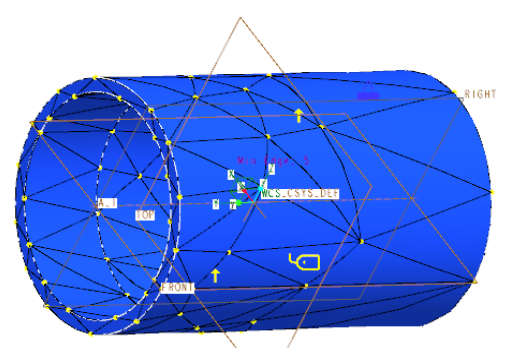

Figure 2. The reseau plot of the three-dimensional model. 


\subsubsection{The result analysis}

Through finite element analysis and the static analysis to cone, the results in Figure 3.

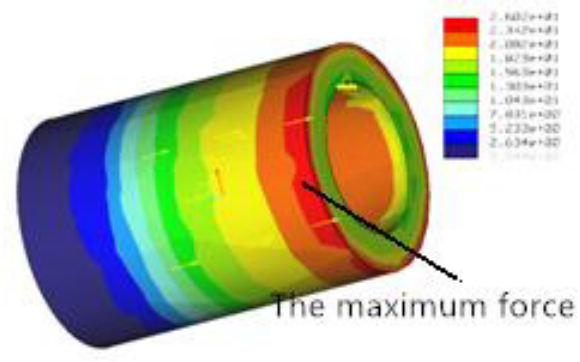

a.Stress envelope

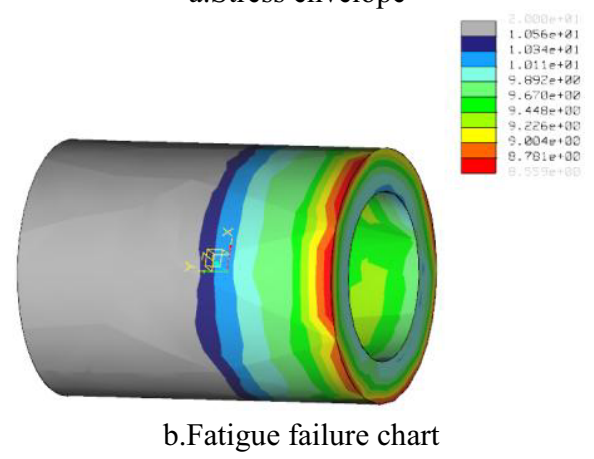

Figure 3. The results of statical and fatigue analysis.

As shown in Figure 3-a, the right edge forming cone by large stress. According to the diagram shows the maximum stress is $6.02 \mathrm{MPa}$. Less than the allowable limit of material. Not destroyed under static loads.But because the molding machine work is a move in circles process. So it takes into account the sleeve of the fatigue failure and the fatigue analysis of sleeve.

\subsection{Fatigue analysis of the ceramic forming cone}

Assuming the load types for the same amplitude. Zero peak amplitude type. The maximum tensile strength of material for $160 \mathrm{MPa}$. Material surface treatment is already glazing. Ceramic is selected to constitute the material. The expected number of cycles is set to 10000 and the strength reduction factor is set to 2 . Through the fatigue failure chart can be seen by Figure 3-b, the right end of the early fatigue failure. By comparison with figure $3-\mathrm{a}$, can find the distribution of the maximum stress position and the fatigue failure position is basically the same. From the point of view of fatigue, forming cone cylinder of the structure and material can satisfy the use requirement.

\section{Sensitivity analysis of cone angle}

Because the molding machine cone cone angle and the cone length of forming cone structure has a great influence. In molding equipment in existing due to different kinds of biomass. With different lignin content needs different forming pressure. The requirements of the shaping sleeve cone angle is not the same. Forming set of cone angle and the effect each feeding biomass before and after the volume ratio, molding pressure and molding rod density. When forming certain set of cone angle, increase the forming sleeve taper length. Or forming sleeve cone length, increase the cone angle of the molding set. After forming the molding rod density larger. Forming pressure required for high, energy consumption ${ }^{[10]}$. Biomass of the species is not considered here. The use of analytical tools sensitivity in $\mathrm{pro} / \mathrm{E}$, study on the influence of design parameters on the performance of the sleeve model, in order to improve. In the design process of forming cone, forming cone cone angle is an important parameter affecting forming cone cylinder service life and shaping effect. Therefore carries on the parameter sensitivity analysis.

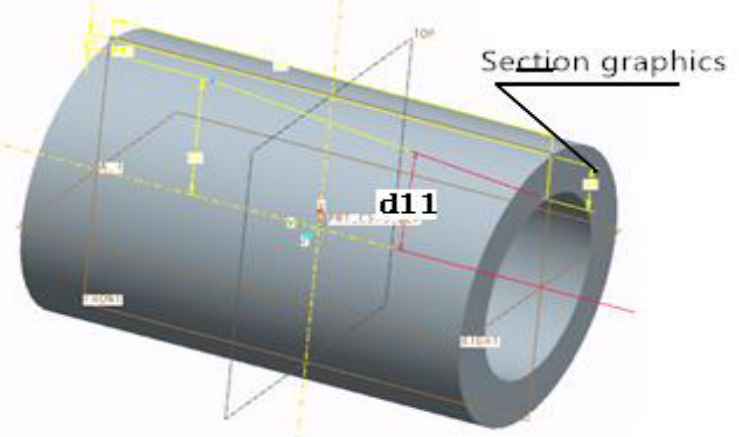

Figure 4. The cone angle.

To the main design parameters of the existing HPB-type IV biomass briquetting machine based on, forming cone tube length $260 \mathrm{~mm}$, the cone angle of 11.4 , big hole forming cone end punch set with a smooth transition diameter zone. When the cone angle is changed,the diameter of zone length change, without affecting the sleeve big hole end small hole diameter. Although there is a change in the length of the taper hole. But because of the existence of such diameter, can make the sleeve length remain unchanged. Effect also can ignore the taper length change. And the sleeve length, it can be used as a standard component of sleeve, convenient to replace.

Here, in order to facilitate the structural model, the size of the cone angle is represented by the $\theta / 2$. Section of the sleeve as shown in Figure 1.4, namely the icon size d11. Due to the large hole end matched the punch rod, so the diameter of the general does not change. The smaller hole end and conservation type cylinder, for convenience of analysis, its size set to a fixed value. The range of variation of $\theta / 2$ is $5 \sim 7$, a total of 11 point measurement. Through the calculation of Pro/E can be obtained sensitivity curve as shown in Figure 5. 


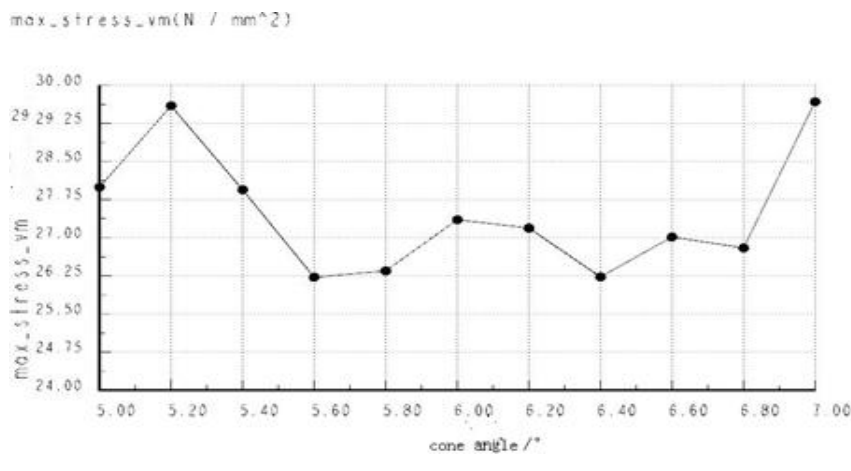

Figure 5. Max-stress curve with the cone angle changed. We can see from Figure 5, the sleeve of the maximum stress as the angle changes and changes. $\theta / 2$ in less than $5.6^{\circ}$ or greater than $6.9^{\circ}$ stress changes greatly. Between $5.6 \sim 6.9^{\circ}$ or, the maximum stress changes little,so the cone angle should be in the region of values.

In the forming of conical cylinder parameters, the case of certain materials. Also need to take into account the effect of molding machine molding. The cone angle is too small to make biomass blocks to achieve the desired density. Too large will result in blocked in the sleeve material. The serious influence production efficiency. Need to use a prototype for further testing to determine. Through the sensitivity analysis of cone angle, from the point of stress can be concluded:suitable angle is $11.2 \sim$ $13.8^{\circ}$.

\section{Conclusion}

In the forming of conical cylinder parameters, the case of certain materials. Also need to take into account the effect of molding machine molding. The cone angle is too small to make biomass blocks to achieve the desired density. Too large will result in blocked in the sleeve material. The serious influence production efficiency Need to use a prototype for further testing to determine. Through the sensitivity analysis of cone angle, from the point of stress can be concluded:suitable angle is 11.2 $13.8^{\circ}$.

\section{References}

1. B.L. Zhang, T.B. Ren, G.Z. Xu, Solid biomass fuel molding China standard system. Trans. Chin. Soc. Agric. Eng. 26(2), 257-262(2010)

2. Q.L. Li, D.D. Qin, Development and utilization of straw densification briquetting fuel. Renew. Energy 26(5), 116-118(2008)

3. B.L. Zhang, Biomass molding fuel technology and engineering. Sci. Press. (2012)

4. Investigation and evaluation report of nation crop straw resources. Agric. Eng. Tec. New. En. Ind. (2), 2-5(2011)

5. B.L. Zhang, X.T. Wang, Discussion on the key problems in the production and application of straw briquette. Trans. Chin. Soc. Agric. Eng. 24(7), 296$300(2008)$
6. Y.Y. Bi, C.L. Gao, Y.J. Wang, Estimate the amount of Chinese straw resources. Trans. Chin. Soc. Agric. Eng. 25(12), 211-217 (2009)

7. Y.S. Tian, Analysis of the development of Chinese biomass solid forming fuel industry. Agric. Eng. Tec. · New. En. Ind. (2), 13-17(2009)

8. B.L. Zhang, F.M. Fan, B.Q. Li, Analysis of biomass forming fuel technology and industrialization prospects. J. Henan Agric.Univ. 39(1), 111-115 (2005)

9. J.H. Liu, G.H. Wang, B.L. Zhang, Rational thinking on the biomass forming fuel industrialization. Trans. Chin. Soc. Agric. Eng 138-141(2006)

10. X.Q. Ma, Biomass (straw) improved design of molding fuel combustion dynamics and hydraulic straw forming machine. Henan Agric. Univ. 32(2002)

11. X.Q. Ma, Biomass (straw) improved design of molding fuel combustion dynamics and hydraulic straw forming machine. Henan Agric. Univ. 39 (2002)

12. B.L. Zhang, B.Q. Li, C.H. Zhao, Application and research of HPB-I type biomass briquetting machine. J. S. E. 20(3), 234-238(1999)

13. J.J. Fang, S.L. Liu, The dynamic simulation and analysis of engineering MachineryPro/ENGINEER Wildfire Engineering application. Chem. Ind. Press. Bei Jing(2004)

14. L.Y. Zhu, B. Li, Pro/ENGINEER Motion simulation and finite element analysis. Post \& Telecom Press. (2004)

15. Z.B. Zhu, Z.J. Guo, L. Ying, Development and application of alumina ceramic. J. Ceramic. (1), 58(2003) 